\title{
Early preclinical studies of discriminable sedative and hallucinogenic drug effects
}

\author{
Herbert Barry III • James B. Appel
}

Published online: 14 October 2008

(C) Springer-Verlag 2008

\section{Erratum to: Psychopharmacology}

\section{DOI 10.1007/s00213-008-1292-7}

The State University of New York at Buffalo was the site for the initial article on the discriminable effect of LSD, by Hirschhorn and Winter (1971) and for the subsequent articles by Winter (1973, 1974a, 1974b). The Medical College of Virginia (Virginia Commonwealth University) was the site for the articles by Schechter and Rosecrans (1972) and by Hirschhorn and Rosecrans (1974).

The online version of the original article can be found at http://dx.doi. org/10.1007/s00213-008-1292-7.

H. Barry III $(\bowtie)$

University of Pittsburgh,

Pittsburgh, PA, USA

e-mail: barryh@pitt.edu

J. B. Appel

University of South Carolina,

Columbia, SC, USA 